\title{
Capacidad de Dos Líneas Celulares para la Producción de Embriones Clonados mediante Transferencia Nuclear de Células Somáticas
}

\author{
Capacity of Two Cell Lines for the Production of Cloned Embryos by \\ Nuclear Somatic C ell Transfer \\ Jenin V. Cortez ${ }^{1,3}$, Nilton L. Murga ${ }^{1}$, Gleni T. Segura ${ }^{1}$, Lleretny Rodríguez ${ }^{2}$, \\ Héctor V. Vásquez ${ }^{1}$, Jorge L. Maicelo ${ }^{1}$
}

\section{Resumien}

\begin{abstract}
En este estudio se demuestra el uso de la transferencia nuclear de células somáticas para producir los primeros bovinos clonados en el Perú. Se obtuvieron fibroblastos de piel y células de cúmulos de donantes adultos para ser usados como carioplastos; asimismo, ovocitos obtenidos a partir de ovarios de camal fueron madurados in vitro por 24 h. Los ovocitos madurados se incubaron $2 \mathrm{~h}$ en demecolcina $(2.5 \mu \mathrm{g} / \mathrm{ml})$ para promover la formación del cono con el plato metafásico y para orientar la enucleación manual. Se eliminó la zona pelúcida en pronasa $(2 \mathrm{mg} / \mathrm{ml})$ por $3 \mathrm{~min}$. La enucleación fue manual con una microcuchilla dividiendo el óvulo en dos mitades, donde las mitades carentes de núcleo fueron fusionadas por el método «sandwich» (citoplasto-fibroblasto-citoplasto) por electrofusión. Las estructuras reconstruidas se activaron químicamente mediante incubación por $5 \mathrm{~min}$ en $7 \%$ de etanol absoluto, seguido por $5 \mathrm{~h}$ de citocalacina B $(5 \mu \mathrm{g} / \mathrm{ml})$ y cicloheximida $(10 \mu \mathrm{g} / \mathrm{ml})$. Las estructuras se cultivaron durante $7 \mathrm{~d}$ hasta la fase de incubación/eclosión de blastocisto. Siete blastocistos fueron transferidos a seis vacas receptoras sincronizadas siete días después de la ovulación. Se logró la permanencia de cuatro y tres vesículas embrionarias hasta los días 28 y 60, respectivamente. Dos terneras llegaron a nacer a partir de embriones reconstruidos con células de piel y con células de cúmulos. Mediante el análisis de genotipos, utilizando 15 marcadores (SSR) para bovinos, se confirmó que los terneros clonados fueron derivados de las líneas celulares de las donantes.
\end{abstract}

Palabras clave: reproducción asistida; bovino; clonación; transferencia nuclear de células somáticas; clonación hecha a mano

\footnotetext{
${ }^{1}$ Laboratorio de Biotecnología Animal, Reproducción y Mejoramiento Genético, Instituto de Investigación en Ganadería y Biotecnología, Universidad Nacional Toribio Rodríguez de Mendoza, Amazonas, Perú

${ }^{2}$ Departamento de Ciencia Animal, Facultad de Ciencias Veterinarias, Universidad de Concepción, Chile

${ }^{3}$ E-mail: jenin.cortez@untrm.edu.pe
}

Recibido: 27 de febrero de 2017

Aceptado para publicación: 14 de julio de 2017 
This study demonstrates the use of nuclear somatic cell transfer to produce the first cloned cattle in Peru. Skin fibroblasts and cumulus cells from adult donors were obtained for use as carioplasts; likewise, oocytes obtained from ovaries in the slaughterhouse were matured in vitro for $24 \mathrm{~h}$. The mature oocytes were incubated $2 \mathrm{~h}$ in demecolcin $(2.5 \mu \mathrm{g} / \mathrm{ml})$ to promote cone formation with the metaphase plate and to guide manual enucleation. The zona pellucida in pronase $(2 \mathrm{mg} / \mathrm{ml})$ was removed for $3 \mathrm{~min}$. The enucleation was manual with a microblade dividing the ova into two halves, where the nucleus-lacking halves were fused by the «sandwich» method (cytoplast-fibroblastcytoplast). The reconstructed structures were chemically activated by incubation for 5 min in $7 \%$ absolute ethanol, followed by $5 \mathrm{~h}$ of cytochalacin B $(5 \mu \mathrm{g} / \mathrm{ml})$ and cycloheximide $(10$ $\mu \mathrm{g} / \mathrm{ml})$. The structures were cultured for $7 \mathrm{~d}$ until the blastocyst incubation/hatching phase. Seven blastocysts were transferred to six synchronized recipient cows seven days after ovulation. The permanence of four and three embryonic vesicles was achieved until days 28 and 60, respectively. Two calves were born from embryos reconstructed with skin cells and cumulus cells. By the genotype analysis using 15 markers (SSR) for cattle, it was confirmed that cloned calves were derived from donor cell lines.

Key words: assisted reproductive technology; bovine; cloning; somatic cell nuclear transfer; handmade cloning

\section{INTRODUCCIÓN}

La transferencia nuclear de células somáticas (SCNT) es una técnica usada para la multiplicación rápida de germoplasma. 'Dolly' fue la primera oveja clonada con éxito, obtenida a través de células epiteliales mamarias, creando una revolución en la ciencia (Wilmut et al., 1997). Otros investigadores desarrollaron el establecimiento de SCNT para la producción de embriones clonados de diferentes tipos de células, entre ellas, de fibroblastos (Keefer et al., 2001) y de células de la granulosa (Wells et al., 1999). Posteriormente, animales de diversas especies han sido clonados a partir de la SCNT; así, bovinos (Cibelli et al., 1998), cabras (Baguisi et al., 1999), cerdos (Polejaeva et al., 2000) y caballos (Galli et al., 2003).

La clonación tradicional, basada en micromanipuladores, requiere de múltiples pasos, es demandante de tiempo y de alto costo al necesitar sofisticados equipos. Por otra parte, el uso adecuado de estos equipos requiere conocimientos altamente calificados (Vajta et al., 2003). Para superar este problema, se ha desarrollado un proceso libre de micromanipuladores (hand made cloning), que es un procedimiento de clonación que pueden ser utilizado para la SCNT (Jena et al., 2012).

La clonación hecha a mano (HMC) es un proceso simplificado de transferencia nuclear, evitando la necesidad de instrumentos sofisticados y de experiencia técnica. La transferencia nuclear de bovino fue descrita por primera vez con ovocitos libres de zona pelúcida, utilizando células embrionarias (Peura et al., 1998). Años más tarde, la técnica de clonación hecha a mano fue desarrollada para la transferencia de células somáticas (Vajta et al., 2001). Descendencia de animales clonados por la clonación hecha a mano se han logrado en bovinos (Tecirlioglu et al., 2003; Vajta et al., 2003), caballos (Lagutina et al., 2007), cerdos (Du et al., 2005) y búfalos (Selokar et al., 2011). 
El presente trabajo tuvo como objetivo evaluar la capacidad de dos líneas celulares (fibroblastos de piel y células del cumulus), de producir embriones clonados mediante una técnica de transferencia nuclear somática no convencional «hand made cloning» (HMC)

\section{Materiales y Métodos}

\section{Localización del Estudio y Materiales}

El estudio se realizó en el Laboratorio de Biotecnología Animal, Reproducción y Mejoramiento Genético de la Universidad Nacional Toribio Rodríguez de Mendoza, región Amazonas, Perú.

Los productos químicos y medios de cultivo fueron adquiridos de Sigma Chemical Co. (EEUU) y los artículos de plástico desechables de Nunc (Roskilde, Dinamarca), a menos que se especifique lo contrario.

\section{Maduración in vitro de Ovocitos}

Se utilizaron 35 ovarios por repetición, recolectados una vez por semana del matadero local, de vacas Brown Swiss x criollo, de dos o más partos y con condición corporal 2.5-4. Los ovarios fueron transportados al laboratorio $\left(33-35{ }^{\circ} \mathrm{C}\right)$ en solución salina al $0.9 \%$, conteniendo 400 UI penicilina. Se hizo la punción de folículos con tamaños entre 3 y $6 \mathrm{~mm}$, con agujas $18 \mathrm{G}$ acopladas a jeringas.

El líquido folicular fue colectado en tubos de $15 \mathrm{ml}$ y mantenido a $37^{\circ} \mathrm{C}$ por $50-60$ min hasta la selección de los ovocitos. Para la colecta, se decantó el líquido folicular y el sedimento se mezcló con medio de manipulación (TCM199 con $4 \mathrm{mM}$ de bicarbonato, $18 \mathrm{mM}$ de hepes, $10 \%$ de SFB y $50 \mathrm{ig} / \mathrm{mL}$ de gentamicina).

Se seleccionaron los ovocitos grado I y II, que son aquellos que presentan un citoplasma homogéneo, oscuro y abundantes células del cúmulo (no degenerado) (De Loos et al., 1989). Para la maduración, se colocaron entre 25 y 30 ovocitos por pocillo en placas de cuatro pocillos, durante $21 \mathrm{~h} \mathrm{a} 38.5^{\circ} \mathrm{C}$ y atmósfera de $5 \%$ de $\mathrm{CO}_{2}$ en medio TCM199 suplementado con $0.6 \mathrm{mM}$ de glutamina, $0.2 \mathrm{mM}$ de piruvato, $0.01 \mathrm{U} / \mathrm{ml}$ de FSH y LH, $1 \mathrm{ig} / \mathrm{ml}$ de estradiol, $50 \mathrm{ig} / \mathrm{ml}$ de gentamicina, $10 \mathrm{ng} / \mathrm{ml}$ de EGF y $10 \% \mathrm{SFB}$ (Vajta et al., 2001).

\section{Preparación de los Citoplastos}

Los ovocitos fueron transferidos a tubos de $1.5 \mathrm{ml}$ con una solución de $0.3 \mathrm{mg} / \mathrm{ml}$ de hialuronidasa en medio de manipulación. El medio fue agitado con vórtex por 6 min a temperatura ambiente $\left(25^{\circ} \mathrm{C}\right)$ para eliminar las células del cúmulo.

Los ovocitos con primer cuerpo polar y sin daños en la membrana citoplasmática fueron seleccionados para la enucleación. Se adicionó demecolcina ( $2.5 \mathrm{ig} / \mathrm{ml}$ ) al medio de maduración para promover la formación del cono con el plato metafásico, y los ovocitos fueron incubados en el medio con demecolcina por $2 \mathrm{~h}$. Luego, se eliminó la zona pelúcida mediante incubación de los ovocitos a $37^{\circ} \mathrm{C}$ en TCM Hepes ( $2 \%$ SFB) y $2 \mathrm{mg} / \mathrm{ml}$ de pronasa. La placa fue constantemente agitada durante la incubación. Los ovocitos desnudos se transfirieron a gotas de $20 \mu \mathrm{de}$ medio de manipulación (TCM Hepes con $30 \%$ de SFB) en grupos de 10-12 por gota.

La enucleación consistió en la eliminación de una parte del citoplasma que contiene el plato metafásico con la ayuda de una microcuchilla (AB Technology, EEUU). Se seleccionaron las mitades enucleadas con o más del 50\% del volumen citoplasmático original. La manipulación se realizó bajo un estereomicroscopio en aumento 40x utilizando contraste para la visualización del plato metafásico (Olympus, Japón).

\section{Cultivos de Células Somáticas}

La línea celular adulta fue obtenida a partir de una muestra de oreja de una vaca - 


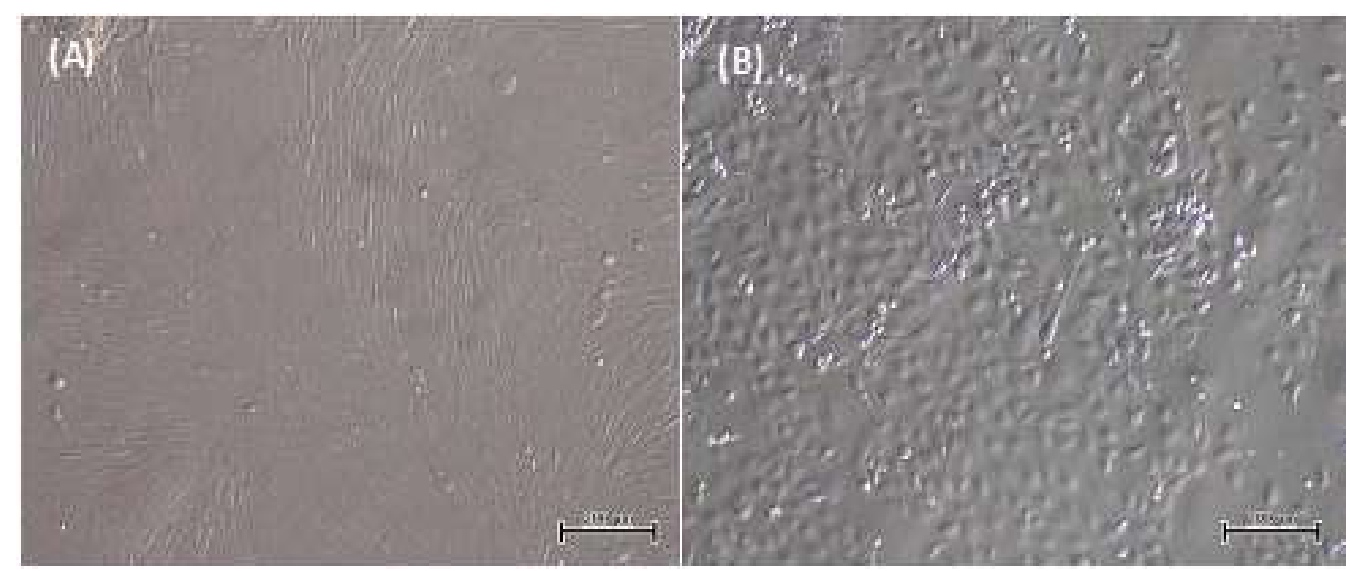

Figura 1. Fibroblastos de piel y células de cumulus en cultivo in vitro: A) Células de piel en confluencia; B) Células del cumulus en crecimiento

Jersey, siguiendo los protocolos establecidos por Tovar et al. (2008). El tejido fue lavado varias veces en buffer fosfato salino (PBS) con antibióticos y fue sometido a digestión por $18 \mathrm{~h}$ en $10 \mathrm{ml}$ de colagenasa $(1 \mathrm{mg} / \mathrm{ml}$ en medio DMEM-F12 suplementado con antibióticos-antimicóticos y $10 \% \mathrm{SFB}$ ) a $37^{\circ} \mathrm{C}$ y con agitación orbital. Luego, el tejido fue agitado vigorosamente para desprender células que aún pudieran encontrarse adheridas al mismo. Se dejó reposar por 3 min y se recuperó el sobrenadante, siendo sembrado en placas Petri de $35 \mathrm{~mm}$ estériles y cultivados por $12 \mathrm{~d}$ (pase 0 ). El volumen del cultivo se completó a $2 \mathrm{ml}$ con medio DMEM-F12 suplementado con $1 \mathrm{mM}$ de glutamina, 0.2 $\mathrm{mM}$ de piruvato, $10 \mathrm{ng} / \mathrm{ml}$ de EGF (epidermal growth factor) y $30 \%$ de suero fetal bovino (SFB).

Las células del cumulus fueron extraídas de ovocitos de una sola donante por aspiración folicular guiada por ecografía (Ovum Pick Up - OPU) (Easote, Italia). Las células fueron separadas por pipeteo constante y luego fueron cultivadas por $5 \mathrm{~d}$ (pase 0 ), como lo descrito para las células de piel.

Transcurrido el periodo de incubación, los cultivos primarios (pase 0 ) fueron expandidos mediante subcultivo $1: 3$ a placas nue- vas empleando tripsina-EDTA al $0.025 \%$ (pase 1) para ambos tipos de células. La acción de la tripsina se detiene adicionando medio de cultivo suplementado con $10 \%$ de SFB. Las células fueron cultivadas hasta alcanzar $100 \%$ de confluencia, donde fueron nuevamente sometidas a la acción de la tripsina, colectadas y congeladas en viales Nalgene de $2 \mathrm{ml}$ (Nalgene, Dinamarca), a razón de $3 \times 10^{6}$ células $/ \mathrm{ml}$ (pase 2) en medio de cultivo suplementado con $10 \%$ SFB y $8 \%$ de DMSO (dimetil sulfóxido). La congelación se llevó a cabo mediante un gradiente de $-1{ }^{\circ} \mathrm{C} / \mathrm{min}$, empleando el sistema Mister Frosty (Nalgene, Dinamarca) en el interior de un congelador comercial de $-80^{\circ} \mathrm{C}$. Luego de $18 \mathrm{~h}$, los viales fueron introducidos a un tanque de nitrógeno líquido $\left(-196^{\circ} \mathrm{C}\right)$. De este modo, se creó un banco maestro congelado con células en pase 2 .

Para el trabajo de rutina, se descongeló un vial del banco maestro, mediante inmersión en baño a $37^{\circ} \mathrm{C}$ por $1 \mathrm{~min}$. Las células se sembraron y cultivaron como se ha descrito y se expandieron 1:5 en pase 3, para posteriormente congelarlas en pase 4 , tal como se describió anteriormente, creando así el banco de trabajo. Para el trabajo de rutina en el laboratorio, se emplearon siempre células descongeladas del banco de trabajo. 


\section{Células de los Donantes}

Como donante de núcleo se utilizaron líneas celulares obtenidas entre los pases $2 \mathrm{y}$ 4. Las células fueron descongeladas a $39^{\circ} \mathrm{C}$ y mantenidas en cultivo sin deprivación de suero, de forma que alcanzaran la confluencia en medio DMEM-F12 más 10\% SFB, para que la mayoría de las células alcancen la fase G0/G1 del ciclo celular por inhibición por contacto.

Para la transferencia nuclear se utilizaron células con al menos $24 \mathrm{~h}$ de confluencia. Solo se utilizaron células con membrana citoplasmática intacta y sin citoplasma granulado ni signos de desprendimiento de la superficie de la placa de cultivo. Una hora antes de la transferencia nuclear, las células fueron colectadas de la placa de cultivo mediante tratamiento con tripsina $0.025 \%$. Las células individualizadas se mantuvieron a temperatura ambiente en un tubo de $1.5 \mathrm{ml}$ con 1 $\mathrm{ml}$ de medio de cultivo hasta el momento de la reconstrucción de los embriones.

\section{Vinculación y Electrofusión de Células del Donante y Citoplastos}

La reconstrucción y la fusión se realizaron por el método «sandwich», que consiste en adherir una célula somática a una de las mitades enucleadas y posteriormente adicionar un segundo citoplasto enucleado. Para ello, la primera mitad de citoplasto se incubó por $5 \mathrm{~s}$ en una solución de $1 \mathrm{mg} / \mathrm{ml} \mathrm{de}$ fitohemoaglutinina (PHA) en TCM Hepes sin SFB. El complejo citoplasto-célula-citoplasto se fundió mediante un pulso de corriente directa de $100 \mathrm{~V}(2 \mathrm{kV} / \mathrm{cm})$ durante $9 \mu$ s en medio de fusión de $0.3 \mathrm{M}$ de manitol, 0.05 $\mathrm{mM}$ de $\mathrm{CaCl}_{2}, 0.1 \mathrm{mM}$ de $\mathrm{MgCl}_{2}$ y $1 \mathrm{mg} / \mathrm{ml}$ de polivinilalcohol (PVA). Se utilizó un electrofusor BLS (Hungría; http://www.blsltd.com) y cámara de fusión BTX de $0.5 \mathrm{~mm}$ de separación entre electrodos (450; BTX Corp, EEUU). Los complejos se pasaron a una gota con medio TCM Hepes más $20 \%$ SFB. La fusión se evaluó 30 min posterior al pulso eléctrico y se seleccionaron los embriones reconstruidos sin signos de lisis.

\section{La Activación y el Cultivo in vitro de Em- briones}

Para la reprogramación nuclear, los presuntos embriones se incubaron por $2 \mathrm{~h}$ a $38.5^{\circ} \mathrm{C}$ y atmósfera de $5 \%$ de $\mathrm{CO}_{2}$ en medio TCM199 con $10 \%$ de SFB. Posteriormente el complejo reconstruido fue activado químicamente mediante la incubación durante $5 \mathrm{~min}$ a temperatura ambiente en $7 \%$ de etanol absoluto en medio TCM Hepes más $20 \% \mathrm{SFB}$, seguido por $5 \mathrm{~h}$ de incubación a $38.5^{\circ} \mathrm{C}$ y atmósfera de $5 \%$ de $\mathrm{CO}_{2}$ en medio TCM199 más $5 \mu \mathrm{g} / \mathrm{ml}$ de citocalacina B y $10 \mu \mathrm{g} / \mathrm{ml}$ de cicloheximida para inhibir la síntesis de proteínas. Una vez finalizada la activación, los embriones reconstruidos se cultivaron durante $7 \mathrm{~d}$, hasta estadio de blastocisto.

Los embriones se cultivaron de forma individual en sistema de cultivo «well on the well» (Vajta et al, 2000) en medio SOF, suplementado con $0.4 \mathrm{mM}$ piruvato de sodio, $0.2 \mathrm{mM}$ de L-glutamina, $1 \mathrm{X}$ de aminoácidos esenciales y no esenciales, $10 \mathrm{ng} / \mathrm{ml}$ de EGF, $2 \%$ de SFB, $0.1 \mathrm{mg} / \mathrm{ml}$ de ácido cítrico, 0.5 $\mathrm{mg} / \mathrm{ml}$ de myo-inositol y $0.3 \%$ de albúmina sérica bovina (BSA) libre de ácidos grasos. La placa de cultivo se selló en una bolsa hermética y se gasificó con una mezcla de aire que contiene $5 \% \mathrm{CO}_{2}, 5 \% \mathrm{O}_{2}$ y $90 \%$ de $\mathrm{N}_{2}$, y se le mantuvo en una incubadora a $38.5^{\circ} \mathrm{C}$ durante todo el periodo de cultivo. No se evaluó la división a las $24 \mathrm{~h}$ para evitar cambios en el pH y temperatura del medio de cultivo.

\section{Sincronización de Receptoras}

Las receptoras fueron sometidas a un protocolo de sincronización de estro/ovulación. En el día 0, se aplicó progesterona 1.38 $\mathrm{g}\left(\mathrm{CIDR} \AA^{\circledR}\right.$, Pfizer $)$ más benzoato de estradiol $2 \mathrm{mg}$ (Estrovet ${ }^{\circledR}$, Montana). En el día 5 día se aplicó prostaglandina $\mathrm{F}_{2 \mathrm{a}}$ como luteolítico $25 \mathrm{mg}$ (Lutalyse ${ }^{\circledR}$, Pfizer) más 400 UI de $\mathrm{EcG}$ (Folligon ${ }^{\circledR}$, Intervet). En el día 8 se reti- 
raron los implantes y en el día 9 se aplicó 1 $\mathrm{mg}$ de benzoato de estradiol con la finalidad de sincronizar la ovulación. Las receptoras presentaron celo en el día 10 y la transferencia de embriones se realizó en el día 17.

\section{Transferencia de Embriones}

Se confirmó por recto-palpación que las receptoras tuvieran un cuerpo lúteo en uno de los ovarios $(\mathrm{CL}>16 \mathrm{~mm})$. Los embriones fueron transferidos con una pistola de transferencia de embriones (21") con fundas punta de acero (Agtech, EEUU) cubierta con camiseta sanitaria. La pistola fue dirigida al cuerno ipso-lateral del CL funcional y el embrión fue depositado en el tercio craneal del cuerno uterino.

\section{Diagnóstico de Gestación}

El diagnóstico de gestación se hizo vía rectal por ultrasonografía (Easote, Italia), con transductor con frecuencia de $7.5 \mathrm{Gz}$, a los 28, 60 y 75 días de transferido el embrión.

\section{Prueba de ADN}

Fue realizado por el Laboratorio de Biología Molecular y Genómica del Instituto de Nacional de Innovación Agraria (INIA), utilizando un panel de 18 marcadores microsatélites recomendados por la ISAG y FAO para pruebas de paternidad: BM1258, BM1314, BM1818, BM1824, BM2113, SSM66, ETH10, ETH225, ETH3, HAUT27, ILSTS006, INRA023, MM12, SPS115, TGLA122, TGLA126, TGLA227 y TGLA53. Los productos amplificados fueron separados por electroforesis capilar (Applied Biosystems, EEUU) y el nombramiento fue realizado con el Programa Genemapper 4.0.

\section{Análisis Estadístico}

Los dos tipos celulares fueron comparados en función a la proporción de tripletes de citoplastos fusionados y la producción de embriones clonados y para ello se aplicó una prueba «t» de Student para muestras o gru- pos de observaciones independientes con un nivel de significancia de 0.05 . Previamente se realizó una prueba de homogeneidad de varianza, además de haberse determinado el comportamiento normal de las observaciones.

\section{Resultados}

Se seleccionaron 1595 ovocitos de grados I y II para el desarrollo de la investigación, de los cuales 1258 (78.8\%) presentaron el primer cuerpo polar después de la maduración in vitro. Al retirarse la zona pelúcida para su manipulación, 575 (45.7\%) ovocitos fueron enucleados.

Se generaron dos líneas celulares para ser usados como carioplastos: fibroblastos de piel adulto y células de cumulus. Se observó diferencia significativa $(p<0.05)$ en la proporción de tripletes de citoplastos fusionados con éxito entre los grupos que utilizaban fibroblastos de piel adultas y células del cumulus (Cuadro 1).

El 80-81\% de los embriones reconstruidos con fibroblastos de piel o células del cumulus llegaron a dividirse, sin diferencias significativas entre tipos de células, aunque las proporciones de embriones que se desa-

Cuadro 1. Citoplastos reconstruidos y fusionados (\%) con fibroblastos de piel y células del cumulus a una hora de su fusión

\begin{tabular}{lcc}
\hline & \multicolumn{2}{c}{ Citoplastos } \\
\cline { 2 - 3 } Células & $\begin{array}{c}\text { Reconstruida } \\
\mathrm{s}(\mathrm{n})\end{array}$ & $\begin{array}{c}\text { Fundidas } \\
(\%)\end{array}$ \\
\hline $\begin{array}{l}\text { Fibroblastos } \\
\text { de piel }\end{array}$ & 145 & $65.8 \pm 6.8^{\mathrm{b}}$ \\
$\begin{array}{l}\text { Células del } \\
\text { cumulus }\end{array}$ & 105 & $86.9 \pm 7.8^{\mathrm{a}}$ \\
\hline $\begin{array}{l}\mathrm{a}, \mathrm{b} \\
\text { Superíndices diferentes dentro de } \\
\text { columnas indican diferencia estadística } \\
(p<0.05)\end{array}$
\end{tabular}


Cuadro 2. Desarrollo de los embriones mediante transferencia nuclear de células somáticas (SCNT) tras su reconstrucción con dos líneas celulares en bovinos

\begin{tabular}{lcccc}
\hline & $\begin{array}{c}\text { Reconstruidos } \\
\text { cultivados } \\
\text { (n) }\end{array}$ & $\begin{array}{c}\text { Clivaje } \\
(\%)\end{array}$ & $\begin{array}{c}\text { Clivaje de } \\
\text { embriones } \\
(\%)\end{array}$ & $\begin{array}{c}\text { Reconstruidos } \\
(\%)\end{array}$ \\
\hline Fibroblastos de piel & 97 & $79.5 \pm 5.1$ & $29.0 \pm 8.4$ & $65.8 \pm 6.8$ \\
Células del cumulus & 91 & $80.7 \pm 5.4$ & $27.9 \pm 10.1$ & $86.9 \pm 7.9$ \\
\hline
\end{tabular}

Cuadro 3. Gestaciones establecidas tras la transferencia de blastocistos clonados obtenidos mediante transferencia nuclear de células somáticas (SCNT) utilizando dos tipos de líneas celulares en bovinos

\begin{tabular}{|c|c|c|c|c|c|}
\hline \multirow{2}{*}{$\begin{array}{l}\text { Células usadas para la } \\
\text { reconstrucción }\end{array}$} & \multirow{2}{*}{$\begin{array}{l}\text { Embriones } \\
\text { transferidos } \\
\text { (n) }\end{array}$} & \multirow{2}{*}{$\begin{array}{l}\text { Receptoras } \\
\text { (n) }\end{array}$} & \multicolumn{3}{|c|}{ Permanencia } \\
\hline & & & $\begin{array}{l}\text { Día } 28 \\
\text { (n) }\end{array}$ & $\begin{array}{l}\text { Día } 60 \\
(\mathrm{n})\end{array}$ & $\begin{array}{l}\text { Día } 75 \\
\text { (n) }\end{array}$ \\
\hline Fibroblastos de piel & 3 & 2 & $2 / 2$ & $1 / 2$ & $1 / 2$ \\
\hline Células del cumulus & 4 & 4 & $2 / 4$ & $2 / 4$ & $1 / 4$ \\
\hline
\end{tabular}

rrollaron en la fase de blastocisto tendieron a ser más bajas con las células de cumulus (Cuadro 2). En total, se reconstruyeron 170 embriones por transferencia nuclear de las dos líneas celulares, produciendo un total de 53 blastocistos al día 7 (28.5\%).

Siete blastocistos viables de día 7 fueron transferidos a seis receptoras sincronizadas en el día 7 después de la ovulación; de estos, tres embriones fueron producidos a partir de fibroblastos de piel y cuatro embriones fueron producidos a partir de células de cumulus. La transferencia se hizo en forma individual o por parejas, dependiendo de la calidad de los embriones (Stringfellow et al., 2010) (Cuadro 3). En el día 28 de la gestación, se pudo observar las vesículas embrionarias en las dos receptoras con embriones reconstruidos a partir de fibroblastos de piel, mientras que en las cuatro recepto- ras que fueron transferidas con embriones reconstruidos con células del cumulus, solo en dos de ellas se encontraban estas vesículas.

Uno de los embriones reconstruidos con fibroblastos de piel se perdió entre los días 58-60 de la gestación, mientras que el otro llegó a término (Cuadro 3). En el caso de los dos embriones detectados en el día 28 de la gestación logrados a partir de las células del cumulus, uno se perdió entre los días 64-68 de la gestación, mientras que el otro llegó a término (Cuadro 3).

Dos de las gestaciones en las receptoras llegaron a término. Una ternera hembra llamada Alma C1 (Figura 2A), Jersey, nació por parto natural el 19 de junio de 2016, con $24 \mathrm{~kg}$, luego de 378 días de gestación. La otra hembra llamada Alta Gracia C1 (Figura 2B) 
Cuadro 4. Análisis de marcadores (SSR) de bovinos clonados, tejido de piel, folículo piloso, receptoras

\begin{tabular}{|c|c|c|c|c|c|c|c|c|c|c|c|c|}
\hline \multirow{3}{*}{$\begin{array}{l}\text { Marcador } \\
\text { genético }\end{array}$} & \multicolumn{2}{|c|}{ Alma } & \multicolumn{2}{|c|}{ Alma-C1 } & \multicolumn{2}{|c|}{$\begin{array}{c}\text { Receptora } \\
1\end{array}$} & \multicolumn{2}{|c|}{ Altagracia } & \multicolumn{2}{|c|}{$\begin{array}{l}\text { Altagracia- } \\
\quad \mathrm{C} 1\end{array}$} & \multicolumn{2}{|c|}{$\begin{array}{c}\text { Receptora } \\
2\end{array}$} \\
\hline & \multicolumn{2}{|c|}{ BT-184 } & \multicolumn{2}{|c|}{ BT-185 } & \multicolumn{2}{|c|}{ BT-186 } & \multicolumn{2}{|c|}{ BT-190 } & \multicolumn{2}{|c|}{ BT-191 } & \multicolumn{2}{|c|}{ BT-192 } \\
\hline & 98 & 100 & 98 & 100 & 98 & 104 & 104 & 104 & 104 & 104 & 104 & 104 \\
\hline BM1314 & & 163 & 163 & 163 & 157 & 159 & & 155 & 155 & 155 & 155 & 157 \\
\hline BM1818 & & 260 & 258 & 260 & 256 & 260 & 258 & 260 & 258 & 260 & 262 & 266 \\
\hline BM1824 & 18 & 182 & 182 & 182 & 182 & 182 & 84 & 190 & 184 & 190 & 180 & 184 \\
\hline BM2113 & & 133 & 133 & 133 & 125 & 133 & 133 & 137 & 133 & 137 & 131 & 133 \\
\hline & & 193 & 193 & 193 & 191 & 199 & 187 & 197 & 187 & 197 & 185 & 187 \\
\hline & & & 21 & 2 & 2 & 217 & & 215 & 215 & 215 & 215 & 215 \\
\hline ETH225 & 14 & 14 & 140 & 144 & 136 & 146 & 146 & 146 & 146 & 146 & 146 & 146 \\
\hline ETH3 & 1 & 123 & 115 & 123 & 115 & 115 & 117 & 119 & 117 & 119 & 119 & 123 \\
\hline & & & & & 1 & 148 & & & 142 & 142 & 42 & 148 \\
\hline & 292 & 294 & 292 & 294 & 288 & 296 & 288 & 292 & 288 & 292 & 294 & 294 \\
\hline INRA023 & 198 & 198 & 198 & 198 & 206 & 206 & 204 & 206 & 204 & 206 & 212 & 212 \\
\hline MM12 & & 125 & 115 & 125 & 115 & 123 & 115 & 127 & 115 & 127 & 115 & 115 \\
\hline & & 250 & 248 & 250 & 244 & 256 & 244 & 248 & 244 & 248 & 244 & 244 \\
\hline TGLA122 & 143 & 151 & 143 & 151 & 151 & 153 & 151 & 163 & 151 & 163 & 143 & 143 \\
\hline TGLA126 & 123 & 123 & 123 & 123 & 117 & 119 & 115 & 117 & 115 & 117 & 115 & 117 \\
\hline TGLA227 & 93 & 95 & 93 & 95 & 81 & 83 & 81 & 99 & 81 & 99 & 89 & 99 \\
\hline TGLA53 & 168 & 168 & 168 & 168 & 160 & 164 & 162 & 166 & 162 & 166 & 158 & 166 \\
\hline
\end{tabular}

nació por cesárea (debido a una deficiente dilatación cervical de la receptora) el 16 de setiembre de 2016, con $58 \mathrm{~kg}$, luego de 390 días de gestación. Las terneras al momento de la presentación del manuscrito continuaban con un desarrollo normal.

Se aisló ADN genómico de folículo piloso de los animales clonados (Alma-C1 y Altagracia-C1) y se comparó con muestras de ADN genómico de piel de las donantes (Alma, Altagracia), y del folículo piloso de las madres sustitutas. Los 18 marcadores (SSR) analizados fueron similares entre los terneros, el folículo piloso y la piel de los donantes (Cuadro 4), mostraron que el ternero era un clon de las células de las donantes utilizadas.

\section{Discusión}

Las células donantes de núcleos (carioplastos) son uno de los principales factores que afectan la eficiencia de la clonación somática. La capacidad de las células de fundirse con el citoplasto receptor y luego ser reprogramadas depende de la línea celular utilizada como donante de núcleo y, esto a su vez, influye en la eficiencia de producción de embriones (Miyoshi et al., 2003).

El estudio demostró diferencias significativas en los porcentajes de fusión de las dos líneas celulares. Asimismo, indirectamente se demostró que la membrana de las células donantes no fue afectada por el aislamiento 


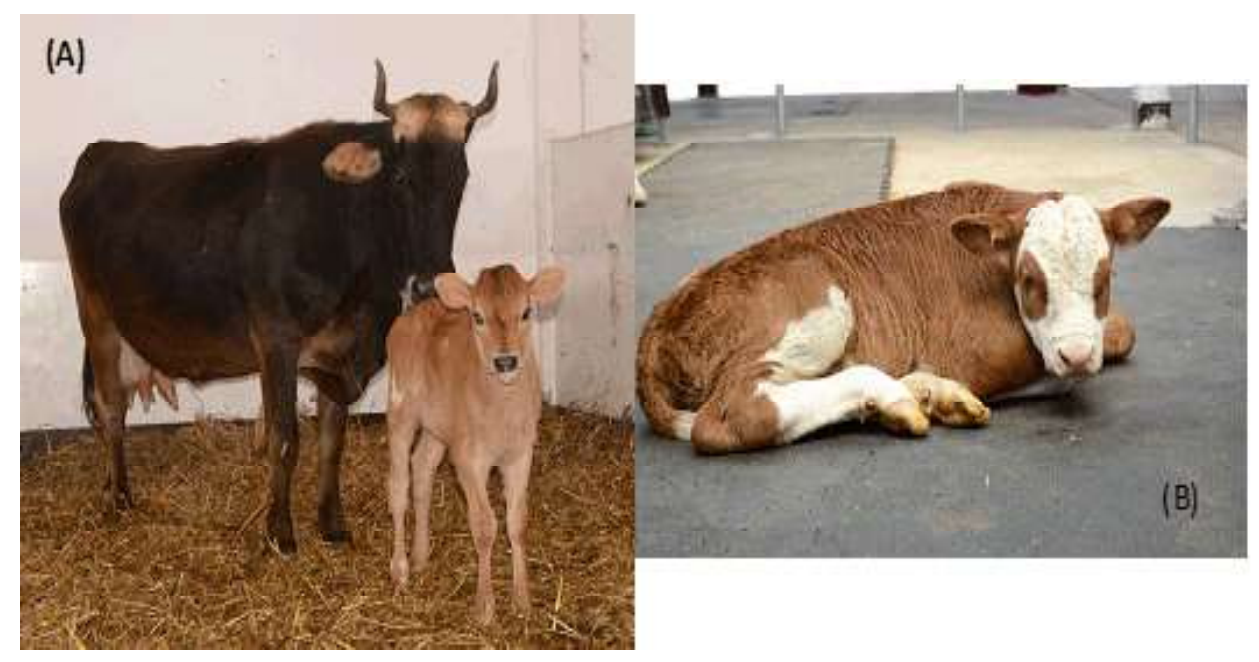

Figura 2. Los terneros clonados mediante la técnica mediante transferencia nuclear de células somáticas (SCNT). A: Tenera Jersey Alma-C1, en el día del nacimiento. B) Ternera Simmental Altagracia-C1

de la línea celular durante las rutinas de trabajo con las células (cultivo in vitro, congelación y descongelación), ni por el pulso eléctrico durante la fusión. Estos resultados coinciden con el trabajo de Hayes et al. (2005). Daños considerables en las membranas como producto de la congelación se reflejan en una disminución significativa en los porcentajes de fusión (34.2 vs. 13.1\%). Los porcentajes de fusión obtenidos (65.8 vs. $86.9 \%)$ de las dos líneas celulares fueron superiores a los reportados para la técnica de clonación con micromanipuladores, independientemente de las células donantes (Hayes et al., 2005) y similares a los reportados para HMC en bovinos (Vajta et al., 2003).

Por otra parte, la producción de blastocistos no dependió de la eficiencia de fusión ni de la sobrevida de los embriones reconstruidos. Los dos grupos de transferencia nuclear produjeron blastocistos al día 7 con una alta eficiencia, aunque con una ligera mayor proporción con el empleo de fibroblastos de piel. En la literatura, los resultados más eficientes de producción de blastocistos bovinos mediante transferencia nuclear somática con micromanipuladores, se encuentran alrededor de un 30\% (First et al., 2002). Los datos publicados de producción de clones mediante HMC aún son muy escasos, incluso en bovinos; pero dentro de estos, los mejores resultados de producción de blastocistos han sido obtenidos por Vajta $e t$ al. (2003) con 52\% con una línea celular fetal y $49 \%$ con células de la granulosa, siendo estos investigadores quienes establecieron esta técnica de clonación en bovinos. Li et al. (2006) posteriormente establecieron esta técnica en porcinos.

\section{Conclusiones}

- Se reporta por primera vez en Perú el establecimiento de gestaciones y nacimientos de bovinos clonados mediante el uso de la técnica de transferencia nuclear de células somáticas (SCNT).

- Se demuestra que los fibroblastos de piel y células del cúmulo pueden cultivarse, expandirse y congelarse sin perder su capacidad de soportar el desarrollo de embriones por transferencia nuclear somática (TNS). 


\section{Agradecimientos}

Los autores agradecen a la Universidad Nacional Toribio Rodríguez de Mendoza de Amazonas y al Instituto de Investigación en Ganadería y Biotecnología las facilidades prestada para el desarrollo del estudio.

\section{Literatura Citada}

1. Baguisi A, Behboodi E, Melican DT, Pollock JS, Destrempes MM, Cammuso C, Williams JL, et al. 1999. Production of goats by somatic cell nuclear transfer. Nat Biotechnol 17: 456461. doi: $10.1038 / 8632$

2. Cibelli JB, Stice SL, Golueke PJ, Kane JJ, Jerry J, Blackwell C, Ponce de Leon FA, Robl JM. 1998. Cloned transgenic calves produced from nonquiescent fetal fibroblasts. Science 280: 1256-1258. doi: 10.1126/science.280.5367 .1256

3. De Loos F, van Vliet C, van Maurik P, Kruip TH. 1989. Morphology of immature bovine oocyte. Gamete Res 24: 197-204. doi: 10.1002/mrd.1120240207

4. Du Y, Kragh PM, Zhang X, Purup S, Yang H, Bolund L, Vajta G. 2005. High overall in vitro efficiency of porcine hand-made cloning (HMC) combining partial zona digestion and oocyte trisection with sequential culture. Cloning Stem Cells 7: 199-205. doi: 10.1089/ clo.2005.7.199

5. First N, Beyhan Z, Ambroggio J. Cloning of cattle. In: Cibelli J, Lanza R, Campbell K, West M (eds). Principles of cloning. San Diego, USA: Academic Press. p 375-390.

6. Galli C, Lagutina I, Crotti G, Colleoni $S$, Turini P, Ponerato N, Duchi R, Lazzari $G$ 2003. Pregnancy: a cloned horse born to its dam twin. Nature 424: 635. doi: $10.1038 / 424635 \mathrm{a}$

7. Hayes O, Ramos B, Rodríguez LL, Aguilar A, Badía T, Castro FO. 2005. Cell confluency is as efficient as serum starvation for inducing arrest in the $\mathrm{G} 0$ /
G1 phase of the cell cycle in granulosa and fibroblast cells of cattle. Anim Reprod Sci 87: 181-192. doi: 10.1016/j.anireprosci.2004.11.011

8. Jena MK, Malakar D, De AK, Garg S, Akshey YS, Dutta R, Sahu S, et al. 2012. Handmade cloned and parthenogenetic goat embryos: a comparison of different culture media and donor cells. Science 105: 255-262. doi: 10.1016/ j.smallrumres.2012.03.001

9. Keefer CL, Baldassarre H, Keyston $R$, Wang B, Bhatia B, Bilodeau AS, Zhou JF, et al. 2001. Generation of dwarf goat (Capra hircus) clones following nuclear transfer with transfected and nontransfected fetal fibroblasts and in vitro-matured oocytes. Biol Reprod 64: 849-856. doi: 10.1095/ biolreprod64.3.849

10. Lagutina I, Lazzari G, Duchi R, Turini P, Tessaro I, Brunetti D, Colleoni S, et al. 2007. Comparative aspects of somatic cell nuclear transfer with conventional and zona-free method in cattle, horse, pig and sheep. Theriogenology 67: 90-98. doi: 10.1016/ j.theriogenology.2006.09.011

11. Li J, Du Y, Zhang YH, Kragh PM, Purup S, Bolund L, Yang H, Xue QZ, Vajta G. 2006. Chemically assisted handmade enucleation of porcine oocytes. Cloning Stem Cells 8: 241-250. doi: 10.1089/clo.2006.8.241

12. Miyoshi K, Rzucidlo SJ, Pratt SL, Stice SL. 2003. Improvements in cloning efficiencies may be possible by increasing uniformity in recipient oocytes and donor cells. Biol Reprod 68: 1079-1086. doi: 0.1095/biolreprod.102.010876

13. Peura TT, Vajta G 2003. A comparison of established and new approaches in ovine and bovine nuclear transfer. Cloning Stem Cells 5: 257-277. doi: 10.1089/153623003772032772

14. Polejaeva IA, Chen SH, Vaught TD, Page RL, Mullins J, Ball S, Dai Y, et al. 2000. Cloned pigs produced by nuclear transfer from adult somatic cells. Nature 407: 86-90. doi: 10.1038/35024082 
15. Selokar NL, George AP, Saha R, Sharma M, Muzaffer RA, Shah $P$, Palta MS, et al. 2011. Production of interspecies handmade cloned embryos by nuclear transfer of cattle, goat and rat ûbroblasts to buffalo (Bubalus bubalis) oocytes. Anim Reprod Sci 123: 279-282. doi: 10.1016/j.anireprosci.2011.01.008

16. Stringfellow DA, Givens MD, International Embryo Transfer Society. 2010. Manual of the International Embryo Transfer Society: a procedural guide and general information for the use of embryo transfer technology emphasizing sanitary procedures. $4^{\text {th }} \mathrm{ed}$. IETS.

17. Tecirlioglu RT, Cooney MA, Lewis $I M$, Korfiatis NA, Hodgson $R$, Ruddock NT, Vajta G, et al. 2005. Comparison of two approaches to nuclear transfer in the bovine: hand-made cloning with modifications and the conventional nuclear transfer technique. Reprod Fertil Dev 17: 573-585. doi: 10.1071/RD04122

18. Tovar H, Navarrete F, Rodríguez L, Skewes O, Castro FO. 2008. Cold storage of biopsies from wild endangered native Chilean species in field conditions and subsequent isolation of primary culture cell lines. In Vitro Cell Dev Biol Anim 44: 309-320. doi: 10.1007/s11626008-9124-y

19. Vajta G, Lewis IM, Hyttel P, Thouas GA, Trounson AO. 2001. Somatic cell cloning without micromanipulators.
Cloning 3: 89-95. doi: 10.1089/ 15204550152475590

20. Vajta G, Lewis IM, Trounson AO, Purup S, Maddox-Hyttel P, Schmidt M, Pedersen HG, et al. 2003. Handmade somatic cell cloning in cattle: analysis of factors contributing to high efficiency in vitro. Biol Reprod 68: 571578. doi: 10.1095/biolreprod.102.008771

21. Vajta G, Lewis IM, Trounson AO, Purup S, Maddox-Hyttel P, Schmidt $M$, Pedersen HG, Greve T, Callesen H. 2003. Handmade somatic cell cloning in cattle: analysis of factors contributing to high efficiency in vitro. Biol Reprod 68: 571-578. doi: 10.1095/ biolreprod.102.008771

22. Vajta G, Peura TT, Holm P, Paldi A, Greve T, Trounson AO, Callesen $H$. 2000. New method for culture of zonaincluded or zona-free embryos: the well of the well (WOW) system. Mol Reprod Dev 55: 256-264. doi: 10.1002/ (S I C I ) $1098-2795(200003)$ 55:3<256::AID-MRD3>3.0.CO;2-7

23. Wells DN, Misica PM, Tervit HR. 1999. Production of cloned calves following nuclear transfer with cultured adult mural granulosa cells. Biol Reprod 60: 996-1005. doi: 10.1095/biolreprod60.4.996

24. Wilmut I, Schneike AE, McWhir J, Kind AJ, Campbell KHS. 1997. Viable offspring derived from fetal and adult mammalian cells. Nature 385: 810-813. doi: $10.1038 / 385810 \mathrm{a} 0$ 